\title{
Meningkatkan Kemampuan Pemahaman Matematis Siswa SMP melalui Pendekatan Kontekstual
}

\author{
Muhammad Trisapto Sunarto1, Sonia Putri Yesmaya Oria Laa ${ }^{2 *}$, Zanjabila Ar-rahiiqil \\ Mahtuum³, Gabriel Torang Siagian, $^{4}$ M. Afrilianto ${ }^{5}$
}

\author{
1,2*3,4,5 Pendidikan Matematika, IKIP Siliwangi \\ Jalan Terusan Jendral Sudirman, Cimahi, Jawa Barat, Indonesia \\ ${ }^{1}$ trisapto182@gmail.com, ${ }^{2 *}$ sonia5putri@gmail.com, ${ }^{3}$ rahiiqillmahtuum@gmail.com, \\ ${ }^{4}$ toranggabriel98@gmail.com, ${ }^{5}$ muhammadafrilianto1@gmail.com
}

Artikel diterima: 22-02-2020, direvisi: 29-01-2021, diterbitkan: 31-01-2021

\begin{abstract}
Abstrak
Penelitian ini merupakan penelitian tindakan kelas (PTK) dengan tujuan mengetahui pengaruh pendekatan kontekstual terhadap peningkatan pemahaman matematis siswa. Subjek dalam penelitian ini adalah siswa MTs pada salah satu sekolah di Cimahi sebanyak 20 orang siswa. Penelitian ini dilakukan untuk mengetahui sejauh mana siswa mampu memahami pembelajaran materi SPLDV dengan menerapkan pendekatan kontekstual. Penelitian ini dilakukan menggunakan model penelitian spiral dimana penelitian akan dihentikan jika peneliti sudah mendapatkan tujuannya. Peneliti melakukan 2 siklus pembelajaran yang pada setiap siklusnya peneliti dinilai oleh observer. Hasil penelitian ini menunjukan bahwa dalam siklus 1 aktivitas guru memperoleh predikat baik namun, aktivitas siswa masih dalam kategori kurang. Sehingga hasil ketuntasan siswa dalam belajar masih dibawah KKM. Oleh karena itu, peneliti melakukan siklus 2 dimana pada siklus ini terjadi peningkatan baik aktivitas guru, siswa, maupun ketuntasan belajar siswa. Yang memperoleh predikat sangat baik dan baik.

Kata Kunci: Pendekatan Kontekstual, Pemahaman Matematis, Penelitian Tindakan Kelas.
\end{abstract}

\section{Improving the Mathematical Understanding Skills of Junior High School Students through Contextual Approach}

\begin{abstract}
This research is a Classroom Action Research with the aim of knowing the influence of contextual approaches on improving students' mathematical understanding. The subjects in this study were MTs at one of cimahi's 20 schools. This research was conducted to find out the extent to which students are able to understand spldv material learning by applying a contextual approach. This study was conducted using a spiral research model where the research will be discontinued if the researcher has got his goal. Researchers conducted two learning cycles that each cycle was assessed by the observer. The results of this study showed that in cycle 1 teacher activity obtained good predicate however, student activity is still in the category of less. So the results of students' completed learning are still under KKM. Therefore, researchers conducted cycle 2 where in this cycle there was an increase in both teacher activity, students, and student learning completeness. Who earned a very good and good predicate.

Keywords: Contextual Approach, Mathematical Understanding, Classroom Action Research.
\end{abstract}




\section{Pendahuluan}

Salah satu kemampuan yang diperlukan dan wajib diajarkan dalam pembelajaran matematika adalah kemampuan pemahaman matematis (Muliawati \& Sofyan, 2013; Nuraeni \& Afriansyah, 2016; Fitri, Aima, \& Muhlisin, 2017; Yani, dkk., 2018; Setiawan \& Prihatnani, 2020). Dimana hal tersebut juga sesuai dengan pernyataan Hudoyo (2003) yang menyebutkan bahwa tujuan pembelajaran matematika yaitu agar suatu pengetahuan dapat dipahami siswa dengan baik, kompetensi dasar dalam pembelajaran matematika mengenai kemampuan pemahaman matematis antara lain: kemampuan menyerap materi, mengingat konsep, rumus, serta implementasi dalam menyelesaikan suatu masalah lain yang serupa dengan memperkirakan suatu pernyataan, menerapkan rumus, dan teorema dalam suatu penyelesaian masalah (Hendriana, Rohaeti, \& Sumarmo, 2017; Dewi, Sundayana, \& Nuraeni, 2020; Setiyani, Sagita, \& Herdiawati, 2020). Maka dari itu pemahaman matematis siswa perlu diajarkan dan dikembangkan dalam pembelajaran supaya tujuan pembelajaran matematika dapat dicapai dengan baik.

Tapi pada kenyataannya sesuai dengan penelitian yang dilakukan oleh Oktoviani, Widoyani, \& Ferdianto (2019) masih rendahnya kemampuan pemahaman siswa SMP dalam menerapkan konsep atau algoritma materi SPLDV terkait mencari solusi masalah yang diberikan. Dalam penelitian Ferdianto \& Yesino (2019) juga menyebutkan bahwa $43.1 \%$ dari subjek yang mereka teliti masih melakukan kesalahan dalam memahami masalah yang diberikan. Hal tersebut terjadi karena adanya pemahaman konsep yang salah pada siswa (Nuraeni \& Luritawaty, 2017; Arimurti, Praja, \& Muhtarulloh, 2019; Warmi, 2019).

Selain itu, hasil penelitian yang dilakukan oleh Sumarmo (1987) menemukan bahwa skor kemampuan siswa dalam pemahaman dan penalaran matematis masih rendah. Nasution (2011:9) mengatakan rendahnya kemampuan penalaran dan pemahaman siswa ini dikarenakan guru hanya menerapkan materi dan contoh soal rutin yang terus berulang ulang, sehingga ketika diberikan soal non rutin yang berbeda dengan bentuk soal yang biasa diberikan siswa mengalami kesulitan (Edo, 2016; Fuadi, Johar, \& Munzir, 2016; Afriansyah, dkk., 2020; Robiana \& Handoko, 2020)

Pembelajaran konvensional yang masih sering kali diaplikasikan guru membatasi siswa untuk aktif dalam pembelajaran (Nadz \& Haq, 2013; Hibattulloh \& Sofyan, 2014; Ristiani, 2014; Margana, 2016; Lubis, Harahap. \& Nasution, 2019; Wiharso \& Susilowati, 2020), sehingga siswa hanya menerima pengetahuan saja. Akibatnya siswa cenderung hanya menghafal suatu rumus atau konsep tanpa memahami suatu konsep dengan baik (Daryanto \& Rahardjo, 2012; Afriansyah, 2013; Matitaputy, 2016; Suwarto, 2018; 
Jeheman, Gunur, \& Jelatu, 2019; Sari \& Afriansyah, 2020). Bercermin dari masalah tersebut, diperlukan sebuah inovasi pembelajaran yang dapat membuat siswa aktif dalam proses belajar, sehingga konsep-konsep yang diberikan mampu dipahami dengan baik yang kemudian dapat diterapkan dalam menyelesaikan masalah-masalah atau soal soal matematik sesuai dengan pemahaman yang mereka sudah dapat dalam pembelajaran.

Pembelajaran kontekstual yang mengaitkan pembelajaran dengan kehidupan nyata dan membawa siswa untuk menggunakan pengalaman kehidupannya (Lestari \& Madio, 2013; Maryati, 2016; Dewi \& Afriansyah, 2018; Agnesti \& Amelia, 2020) untuk menyelesaikan masalah matematika yang ada menjadi salah satu solusi untuk meningkatkan keaktifan siswa dalam pembelajaran, hal itu sesuai dengan penelitian yang dilakukan oleh Brinus, Makur, \& Nendi (2019) bahwa pembelajaran kontekstual mampu meningkatkan kemampuan pemahaman siswa SMPN 4 Langke Rembong kelas VII dikarenakan pada pembelajaran kontekstual terdapat hubungan antara materi dengan kehidupan sehari hari .

Oleh karena itu, pembelajaran dengan pendekatan kontekstual perlu diimplementasikan pada pembelajaran SPLDV di MTs Nurul Iman Cimahi. Siswa dapat membuat model matematika yang sesuai dengan permasalahan yang ada. Kemudian siswa dibimbing untuk untuk membuat pertanyaan yang muncul dari suatu permasalahan, setelah itu siswa membangun sendiri pemahaman yang ia dapat dari masalah secara terstruktur. Pengalaman tersebutlah yang nantinya dapat terkenang baik oleh siswa karena mereka mendapatkan pengetahuan dari pemahaman yang mereka dapatkan, sehingga pengetahuan itu akan lebih lama tersimpan dalam memori meraka.

Berdasarkan uraian di atas, maka penelitia berniat untuk meneliti pengaruh pemahaman matematis siswa yang menggunakan pendekatan kontekstual di MTs Nurul Iman Cimahi.

\section{Metode}

Penelitian ini menggunakan metode penelitian tindakan kelas (PTK) dimana dalam setiap siklus dan setiap pertemuannya terdiri atas perencanaan tindakan, pelaksanaan tindakan dan yang terakhir akan diadakan evaluasi sebagai bahan perbaikan maupun refleksi untuk memperbaiki pembelajaran yang sudah diberikan kepada siswa sebelumnya (Hendriana \& Afrilianto, 2017). Penelitian yang dilaksanakan dikelas diimplementasikan sebanyak dua siklus. Karakteristik yang digunakan disesuaikan dengan masalah yang harus dipecahkan dan berasal dari persoalan praktik pembelajaran dikelas atau factual.

Model Kemmis \& MC Taggart menjadi rujukan dalam penelitian tindakan kelas yang mengatakan bahwa tindakan yang digambarkan dan dilaksanakan merupakan 
suatu proses dinamis dari hal hal yang yang berkaitan dengan perencanaan, tindakan, observasi dan refleksi. Model penelitian ini disebut dengan model penelitian spiral dimana penelitian akan dihentikan jika peneliti sudah mendapatkan tujuannya.

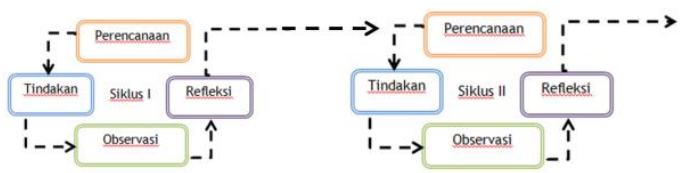

Gambar 1. Model Penelitian Kemmis \& MC Taggart

Subyek penelitian dalam penelitian ini adalah siswa di kelas VIII MTs Nurul Iman Cimahi. Dengan siswa sebanyak 20 siswa terdiri dari 10 siswa laki-laki dan 10 siswa perempuan. Data yang dikumpulkan dalam penelitian ini berupa hasil observasi aktivitas guru, observasi kegiatan siswa dan hasil tes yang dilaksanakan diawal dan diakhir setiap siklus. RPP dan LKS dengan pendekatan kontekstual merupakan perangkat pembelajaran yang digunakan dalam penelitian ini.

Data hasil observasi selanjutnya dianalisis dengan skor untuk menentukan kategori. Menurut (Wirahadi, 2019) sebagai berikut :

Persentase ketuntasan belajar klasik $=\frac{\sum \text { Deskriptor yang muncul }}{\sum \text { Deskriptor Maksimal }} \times 100 \%$

Kemudian hasil perhitungan persentase keberhasilan tindakan pada masingmasing tahapan pembelajaran yang diperoleh akan dibandingkan dengan penentuan skor klasifikasi pada Tabel 1 berikut ini:

Tabel 1.

Penentuan Klasifikasi Skor Hasil Observasi

Presentase Keberhasilan Taraf Keberhasilan Tindakan

\begin{tabular}{|cc|}
\hline $85 \%-100 \%$ & Sangat Baik \\
\hline $70 \%-85 \%$ & Baik \\
\hline $65 \%-70 \%$ & Cukup \\
\hline $50 \%-65 \%$ & Kurang \\
\hline $0 \%-50 \%$ & Sangat Kurang \\
\hline
\end{tabular}

Data hasil tes siswa dianalisis dengan membandingkan persentase ketuntasan belajar secara klasikal pada pendekatan kontekstual siklus I dan siklus II. Sedangkan persentase ketuntasan belajar secara klasikal dihitung dengan cara berikut:

Persentase ketuntasan belajar klasikal

$$
=\frac{\sum \text { Siswa yang tuntas }}{\sum \text { Siswa Maksimal }} \times 100 \%
$$

\section{Hasil dan Pembahasan}

Hasil penelitian utama yang digunakan dalam penelitian ini berupa hasil observasi terhadap guru dan juga observasi terhadap siswa, serta tes kemampuan siswa pada materi SPLDV. Berikut merupakan hasil observasi terhadap aktivitas guru, sebagai berikut:

Tabel 2.

Hasil Observasi Aktivitas Guru Pada Siklus I

\begin{tabular}{cccc}
\hline No & Observer & $\begin{array}{c}\text { Skor Siklus } \\
1\end{array}$ & $\begin{array}{c}\text { Presentase Siklus } \\
\text { I }\end{array}$ \\
\hline 1 & Observer & 51 & $78,4 \%$ \\
& 1 & &
\end{tabular}

Pada Tabel 2 dapat terlihat bahwa pada siklus I keberhasilan aktivitas guru dalam menerapkan rencana pembelajaran memperoleh rata-rata $78,4 \%$ sehingga 
dapat dikategorikan baik. Selain aktivitas guru, observer juga mengamati kegiatan siswa dalam belajar yang disesuaikan dengan sintaks ataupun langkah-langkah pembelajaran pada pendekatan kontekstual. Maka diperolehlah hasil analisis kegiatan siswa yang disajikan pada tabel berikut:

Tabel 3.

Hasil Observasi Aktivitas Siswa Pada Siklus I

\begin{tabular}{cccc}
\hline No & Observer & $\begin{array}{c}\text { Skor Siklus } \\
1\end{array}$ & $\begin{array}{c}\text { Presentase Siklus } \\
\text { I }\end{array}$ \\
\hline 1 & Observer & 35 & $63,6 \%$ \\
& 1 & &
\end{tabular}

Berdasarkan Tabel 3 klasifikasi aktivitas siswa pada siklus 1 dapat di kategorikan kurang, hal ini karena rata-rata aktivitas siswa memperoleh $63,6 \%$. Selain meilihat dari hasil observasi terhadap aktivitas guru dan siswa, peneliti juga melakukan tes untuk melihat ketuntasan siswa dalam belajar pada siklus I. Hasil belajar siswa dapat terlihat dalam Tabel berikut:

Tabel 4.

Ketuntasan Belajar Siswa Siklus I

\begin{tabular}{cccc}
\hline $\begin{array}{c}\text { Jumlah } \\
\text { Siswa }\end{array}$ & $\begin{array}{c}\text { Tuntas } \\
\text { Belajar }\end{array}$ & $\begin{array}{c}\text { Belum } \\
\text { Tuntas } \\
\text { Belajar }\end{array}$ & $\begin{array}{c}\text { Ketuntasan } \\
\text { Belajar }\end{array}$ \\
\hline 20 & 0 & 20 & $0 \%$
\end{tabular}

Sesuai dengan Kriteria Ketuntasan Minimum (KKM) yang ditetapkan MTS Nurul Iman, siswa dikatakan tuntas belajar bila hasil tes mencapai lebih dari atau sama dengan 75 . Tentu bila melihat tabel 4 dari 20 orang siswa, belum ada satupun yang dapat mencapai KKM yang telah ditetapkan.
Berdasarkan hasil refleksi pada siklus I ditemukan beberapa kekurangan dalam proses pembelajaran, yaitu peneliti kurang mengorganisasikan waktu dengan baik, siswa masih mengalami kesulitan dalam mengidentifikasi masalah dengan baik, tidak semua siswa aktif merespon dalam penyampaian materi. Melihat kekurangan pada siklus I selanjutnya peneliti melakukan perbaikan dan peningkatan kualitas proses pembelajaran dengan melakukan perbaikan pada siklus II.

Pada siklus II diperoleh hasil observasi aktifitas guru yang tersaji pada tabel berikut:

Tabel 5.

Hasil Observasi Aktivitas Guru Pada Siklus II

\begin{tabular}{cccc}
\hline No & Observer & $\begin{array}{c}\text { Skor Siklus } \\
1\end{array}$ & $\begin{array}{c}\text { Presentase Siklus } \\
\text { । }\end{array}$ \\
\hline 1 & $\begin{array}{c}\text { Observer } \\
1\end{array}$ & 57 & $87,69 \%$ \\
& & &
\end{tabular}

Berdasarkan Tabel 5 rata-rata keberhasilan guru dalam menerapkan rencana pembelajaran dalam siklus II sebesar 87,69\%, bila di klasifikasikan masuk kedalam kategori sangat baik. Data hasil observasi aktifitas siswa pada siklus II tersaji pada Tabel 6 berikut:

Tabel 6.

hasil observasi aktivitas siswa siklus ॥

\begin{tabular}{cccc}
\hline No & Observer & $\begin{array}{c}\text { Skor Siklus } \\
1\end{array}$ & $\begin{array}{c}\text { Presentase Siklus } \\
\text { I }\end{array}$ \\
\hline 1 & $\begin{array}{c}\text { Observer } \\
1\end{array}$ & 45 & $81,81 \%$
\end{tabular}

Penilaian aktivitas siswa menurut observer 1 memperoleh rata-rata keberhasilan sebesar $81,81 \%$. Hal ini bila di 
interpretasikan kedalam penentuan skor klasifikasi observasi masuk kedalam kategori baik. Selain penilaian yang dilakukan oleh observer, peneliti melakukan tes kembali pada tahap siklus II. Hal ini dilakukan untuk mengetahui tingkat ketuntasan siswa dalam belajar. Berikut merupakan hasil ketuntasan belajar siswa dalam siklus II (lihat Tabel 7). Tabel 7. ketuntasan belajar siswa siklus ॥

\begin{tabular}{cccc}
\hline $\begin{array}{c}\text { Jumlah } \\
\text { Siswa }\end{array}$ & $\begin{array}{c}\text { Tuntas } \\
\text { Belajar }\end{array}$ & $\begin{array}{c}\text { Belum } \\
\text { Tuntas } \\
\text { Belajar }\end{array}$ & $\begin{array}{c}\text { Ketuntasan } \\
\text { Belajar }\end{array}$ \\
\hline 20 & 13 & 7 & $65 \%$
\end{tabular}

Berdasarkan Standar Ketuntasan Belajar Minimum di Mts Nurul Iman, yaitu siswa dikatakan tuntas belajar jika nilai tes telah mencapai nilai 75. Dilihat dari tabel di atas, 65\% siswa telah tuntas belajar. Karena lebih dari $65 \%$ siswa tuntas belajar, maka dapat dikatakan bahwa ketuntasan belajar siswa belum dicapai dengan maksimal namun siswa mengalami peningkatan dalam ketuntasan belajar, terjadi peningkatan antara sebelum dan sesudah dilakukan perlakuan dengan metode penelitian tindakan kelas menggunakan pendekatan kontekstual.

Berdasarkan PTK yang telah dilaksanakan terlihat bahwa pendekatan kontekstual yang diimplementasikan dikelas selama dua siklus ini mempengaruhi pemahaman matematis siswa dalam materi SPLDV, seperti dalam penelitian Sugandi \& Bernard (2018) bahwa implementasi pendekatan kontekstual pada pembelajaran matematika berpengaruh baik dan dapat meningkatkan pemahaman matematis siswa dibandingkan dengan pendekatan konvensional. Sejalan dengan penelitian tindakan kelas yang diadakan oleh Sarbiyono (2020) selama tiga kali siklus didapati adanya peningkatan aktivitas dan prestasi belajar siswa dengan menggunakan pendekatan kontekstual

\section{Penutup}

Penelitian Tindakan Kelas pada penelitian ini melalui dua siklus pembelajaran dalam materi SPLDV. Didapat bahwa penggunaan pendekatan kontekstual yang dilakukan pada kedua siklus mempengaruhi pemahaman matematis siswa. Hal ini tercermin dari meningkatnya keberhasilan aktivitas guru dan siswa sehingga mempengaruhi ketuntasan belajar siswa.

Diharapkan untuk peneliti lain yang akan melaksanakan Penelitian Tindakan Kelas dapat lebih memperhatikan penggunaan waktu dengan baik, mencari solusi agar siswa dapat lebih aktif dalam pembelajaran. Selain itu, Penelitian Tindakan Kelas yang akan dilakukan dapat dilaksanakan dalam jangka waktu yang lebih lama lagi, agar karakteristis siswa lebih terlihat dan proses pembelajaran memberikan hasil yang lebih maksimal.

\section{Daftar PUSTAKa}

Afriansyah, E. A. (2013). Design Research: Place Value in Decimal Numbers 
Using Metric System. In International Seminar on Mathematics, Science, and Computer Science Education MSCEIS, Universitas Pendidikan Indonesia (UPI) Bandung.

Afriansyah, E. A., Herman, T., Turmudi, T., \& Dahlan, J. A. (2020). Mendesain Soal Berbasis Masalah untuk Kemampuan Berpikir Kritis Matematis Calon Guru. Mosharafa: Jurnal Pendidikan Matematika,9(2), 239250.

Agnesti, Y., \& Amelia, R. (2020). Penerapan Pendekatan Kontekstual dalam Menyelesaikan Soal Cerita pada Materi Perbandingan dan Skala terhadap Siswa SMP. Mosharafa: Jurnal Pendidikan Matematika, 9(2), 347-358.

Arimurti, I., Praja, E. S., \& Muhtarulloh, F. (2019). Desain Modul Berbasis Model Discovery Learning untuk Kemampuan Pemahaman Matematis Siswa. Mosharafa: Jurnal Pendidikan Matematika, 8(3), 459-470.

Brinus, K. S. W., Makur, A. P., \& Nendi, F. (2019). Pengaruh Model Pembelajaran Kontekstual terhadap Pemahaman Konsep Matematika Siswa SMP. Mosharafa: Jurnal Pendidikan Matematika, 8(2), 270. https://doi.org/10.31980/mosharafa. v8i2.439

Daryanto, \& Rahardjo, M. (2012). Model Pembelajaran Inovatif. Yogyakarta: Gava Media.

Dewi, S. S. S., \& Afriansyah, E. A. (2018). Kemampuan Komunikasi Matematis Siswa Melalui Pembelajaran CTL. JIPMat, 3(2), 145-155.

Dewi, R. S., Sundayana, R., \& Nuraeni, R. (2020). Perbedaan Peningkatan
Kemampuan Komunikasi Matematis dan Self-Confidence antara Siswa yang Mendapatkan DL dan PBL. Mosharafa: Jurnal Pendidikan Matematika, 9(3), 463-474.

Edo, S. I. (2016). Jenis kekeliruan akibat menghafal prosedur rutin dalam melakukan operasi penjumlahan dan pengurangan bilangan pecahan. Mosharafa: Jurnal Pendidikan Matematika,5(3), 223232.

Ferdianto, F., \& Yesino, L. (2019). Analisis Kesalahan Siswa dalam Menyelesaikan Soal pada Materi SPLDV Ditinjau dari Indikator Kemampuan Matematis. Supremum Journal of Mathematics Education.

Fitri, D. Y., Aima, Z., \& Muhlisin, M. (2017). Pengaruh Penerapan Teknik Spotlight terhadap Pemahaman Konsep Matematis Sisiwa Kelas VIII SMPN 1 Batang Anai Padang Pariaman. Mosharafa: Jurnal Pendidikan Matematika,6(2), 247254.

Fuadi, R., Johar, R., \& Munzir, S. (2016). Meningkatkan Kemampuan Pemahaman dan Penalaran Natenatis melalui Pendekatan Kontekstual. Jurnal Didaktik Matematika, 47-54.

Hendriana, H., \& Afrilianto, M. (2017). Langkah Praktis Penelitian Tindakan Kelas Bagi Guru (1st ed.; D. Sumayyah, ed.). Bandung: PT. Refika Aditama.

Hendriana, H., Rohaeti, E. S., \& Sumarmo, U. (2017). Hard Skills dan Soft Skills (RF.PDK.83.; N. F. Atif, ed.). Bandung: PT. Refika Aditama.

Hibattulloh, N., \& Sofyan, D. (2014). Perbandingan Kemampuan 
Komunikasi Matematis Siswa Antara Yang Menggunakan Model Pembelajaran Kooperatif Tipe Jigsaw Dengan Konvensional. Mosharafa: Jurnal Pendidikan Matematika, 3(3), 169-178.

Hudoyo, H. (2003). Pengembangan Kurikulum dan Pembelajaran Matematika. Malang: Jurusan Matematika FMIPA UNM.

Jeheman, A. A., Gunur, B., \& Jelatu, S. (2019). Pengaruh Pendekatan Matematika Realistik terhadap Pemahaman Konsep Matematika Siswa. Mosharafa: Jurnal Pendidikan Matematika, 8(2), 191-202.

Lestari, N., \& Madio, S. S. (2013). Perbedaan Prestasi Belajar Matematika Siswa antara yang Mendapatkan Model Pembelajaran Kooperatif Tipe Jigsaw dan Kontekstual. Mosharafa: Jurnal Pendidikan Matematika,2(3), 169178.

Lubis, R., Harahap, T., \& Nasution, D. P. (2019). Pendekatan Open-Ended dalam Membelajarkan Kemampuan Koneksi Matematis Siswa. Mosharafa: Jurnal Pendidikan Matematika, 8(3), 399-410.

Margana, A. (2016). Pengaruh Penggunaan Model Pembelajaran Problem Based Instruction terhadap Kemampuan Pemecahan Masalah Matematik Siswa. Mosharafa: Jurnal Pendidikan Matematika, 5(1), 18-25.

Maryati, I. (2016). Upaya Meningkatkan Kemampuan Pemecahan Masalah Matematik Siswa Sekolah Menengah Pertama Melalui Pembelajaran Kontekstual. Mosharafa: Jurnal Pendidikan Matematika, 5(1), 1-9.
Matitaputy, C. (2016). Miskonsepsi Siswa dalam Memahami Konsep Nilai Tempat Bilangan Dua Angka. Mosharafa: Jurnal Pendidikan Matematika, 5(2), 113-119.

Muliawati, T., \& Sofyan, D. (2013). Perbandingan Kemampuan Pemahaman Matematis antara Siswa yang Mendapatkan Strategi Creative Problem Solving (CPS) dengan Model Pembelajaran

Konvensional. Mosharafa: Jurnal Pendidikan Matematika, 2(1), 55-64.

Nadz, T. F., \& Haq, C. N. (2013). Perbandingan Peningkatan Kemampuan Penalaran Matematis Siswa yang Memperoleh Pembelajaran melalui Metode Problem Based Instruction (Pbi) dengan Metode Konvensional. Mosharafa: Jurnal Pendidikan Matematika,2(3), 191202.

Nuraeni, Y., \& Afriansyah, E. A. (2016). Peningkatan Kemampuan Pemahaman Matematis Siswa Melalui Pembelajaran Kooperatif Tipe Rotating Trio Exchange. Jurnal Inovasi Pendidikan Dasar, 1(2), 85-94.

Nuraeni, R., \& Luritawaty, I. P. (2017). Perbandingan Kemampuan Pemahaman Matematis Siswa Antara yang Menggunakan Pembelajaran Inside-Outside-Circle dengan Konvensional. Mosharafa: Jurnal Pendidikan Matematika,6(3), 441450.

Oktoviani, V., Widoyani, W. L., \& Ferdianto, F. (2019). Analisis kemampuan pemahaman matematis siswa SMP pada materi sistem persamaan linear dua variabel. 
Edumatica: Jurnal Pendidikan Matematika, $9(1), \quad 45$. https://doi.org/10.22437/edumatica. v9i1.6346

Ristiani, H. (2014). Perbandingan Kemampuan Pemecahan Masalah Matematis Siswa antara Siswa yang Mendapatkan Model Pembelajaran Two Stay-Two Stray (ts-ts) dengan Konvensional. Mosharafa: Jurnal Pendidikan Matematika,3(2), 109 120.

Robiana, A., \& Handoko, H. (2020). Pengaruh Penerapan Media UnoMath untuk Meningkatkan Kemampuan Komunikasi Matematis dan Kemandirian Belajar Siswa. Mosharafa: Jurnal Pendidikan Matematika, 9(3), 521-532.

Sarbiyono. (2020). Penerapan Pendekatan Kontekstual dan Pemecahan Masalah untuk Meningkatkan Aktivitas dan Prestasi Belajar Matematika. EMTEKA Jurnal Pendidikan Matematika.

Sari, H. M., \& Afriansyah, E. A. (2020). Analisis Miskonsepsi Siswa SMP pada Materi Operasi Hitung Bentuk Aljabar. Mosharafa: Jurnal Pendidikan Matematika, 9(3), 439-450.

Setiyani, S., Sagita, L., \& Herdiawati, I. E. (2020). Penerapan Model Murder Terhadap Peningkatan Kemampuan Analisis Dan Evaluasi Matematis Siswa SMP. Mosharafa: Jurnal Pendidikan Matematika,9(3), 395406.

Setiawan, Y., \& Prihatnani, E. (2020). Perbandingan TAl dan NHT terhadap Hasil Belajar Trigonometri Ditinjau dari Kecerdasan Interpersonal. Mosharafa: Jurnal Pendidikan Matematika,9(2), 299-
310.

Sugandi, A. I., \& Bernard, M. (2018). Penerapan Pendekatan Kontekstual Terhadap Kemampuan Pemahaman Dan Komunikasi Matematis Siswa Smp. Jurnal Analisa, 4(1), 16-23. https://doi.org/10.15575/ja.v4i1.236 $\underline{4}$

Suwarto, S. (2018). Konsep Operasi Bilangan Pecahan melalui Garis Bilangan. Mosharafa: Jurnal Pendidikan Matematika, 7(3), 327336.

Warmi, A. (2019). Pemahaman Konsep Matematis Siswa Kelas VIII pada Materi Lingkaran. Mosharafa: Jurnal Pendidikan Matematika,8(2), 297306.

Wiharso, T. A., \& Susilawati, H. (2020). Meningkatkan Kemampuan Koneksi Matematik dan Self Efficacy Mahasiswa melalui Model CORE. Mosharafa: Jurnal Pendidikan Matematika, 9(3), 429-438.

Wirahadi, U. K. (2019). Meningkatkan Hasil Belajar Matematika Siswa Melalui Strategi Pembelajaran Kooperatif Tipe Tutor Sebaya Untuk Siswa Kelas VII-F SMP Negeri 7 Malang. Journal of Chemical Information and Modeling, 53(9), 1689-1699. https://doi.org/10.1017/CB09781107 415324.004

Yani, C. F., Maimunah, M., Roza, Y., Murni, A., \& Daim, Z. (2019). Analisis Kemampuan Pemahaman Matematis Siswa pada Materi Bangun Ruang Sisi Lengkung. Mosharafa: Jurnal Pendidikan Matematika,8(2), 203214. 


\section{Riwayat Hidup PenUlis}

\section{Muhammad Trisapto Sunarto.}

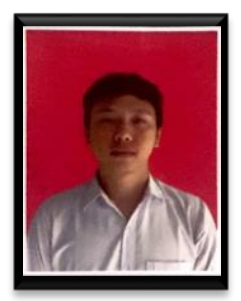

Lahir di Sukabumi, 21 Oktober 1997. Studi S1 Pendidikan Matematika IKIP Slliwangi.

\section{Sonia Putri Yesmaya Oria Laa.}

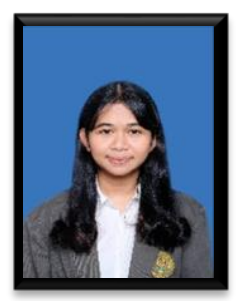

Lahir di Kebumen 5 September 1997. Pernah menempuh studi di SMAN 13 Bandung. Dan sekarang studi S1 Pendidikan Matematika IKIP Slliwangi.

\section{Zanjabila Ar-Rahiiqil Mahtuum.}

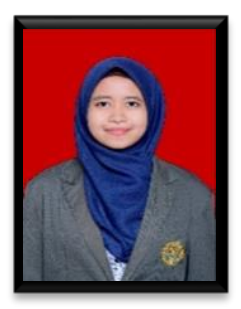

Lahir di Kota Bekasi, 27 Juli 1998. Pernah menempuh studi di SMA Negeri 5 Kota Bekasi. Dan sekarang studi S1 Pendidikan Matematika IKIP Slliwangi.

\section{Gabriel Torang Siagian.}

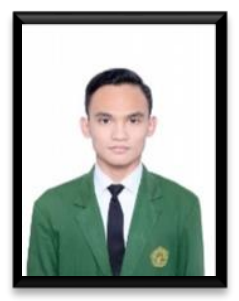

Lahir di Kota Jakarta, 29 Oktober 1998. Dan sekarang studi S1 Pendidikan Matematika IKIP Slliwangi.

\section{Afrilianto, S.Pd., M.Pd.}

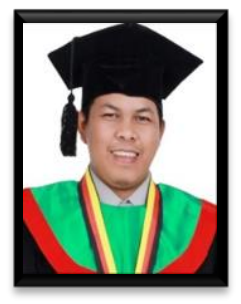

Lahir di Cimahi, 29 April 1986. Staf Pengajar di Program Studi Pendidikan Matematika di IKIP SILIWANGI. S1 Pendidikan Matematika di Universitas Haluoleo, lulus tahun 2009; S2 Pendidikan Matematika di Universitas Pendidikan Indonesia, 